\title{
Level of Individuals' Knowledge About Age-Related Macular Degeneration
}

\author{
Bireylerin Yaşa Bağlı Makula Dejenerasyonu Hakkında Bilgi Düzeyi
}

\author{
Aslıhan Çiflik Bolluk ${ }^{* 1}$, Volkan Bolluk², Nilgün Özçakar ${ }^{1}$
}

\section{ÖZET}

Giriş: Yaşa Bağlı Maküla Dejenerasyonu "YBMD”, gelişmiş ülkelerde 65 yaş ve üzeri kişilerde santral görme kaybının en sık nedenidir. Bireylerin risk faktörlerini bilmesi, yaşam tarzını düzenlemesi önem taşımaktadır. Amaç: Bireylerin YBMD hakkındaki bilgi düzeylerini ölçmek ve farkındalığını artırmak. Yöntem: Çalışmamız kesitsel tanımlayıcı bir araştırma olarak planlanmıştır. Aile Hekimliği polikliniğine Aralık 2015-Mart 2016 tarihlerinde herhangi bir nedenle başvuran 18 yaş ve üstü bireylere sosyo-demografik veriler ve sarı nokta hastalığı hakkındaki bilgi düzeyinin sorgulandığı soruların bulunduğu anket formu yüz yüze görüşme yöntemiyle uygulanmıştır. İstatistiksel analizlerde SPSS 15.0 programı kullanılmış, $\mathrm{p}<0,05$ anlamlı kabul edilmiștir. Bulgular: Araștırmaya katılan 451 kișinin 242 (\%53,7)'si kadındı. Katılımcıların \%55,4'ü sarı nokta hastalığını duymuştu. Sarı nokta hastalığını duyan bireylerin \%27'si çevresindeki insanlardan, \%25'i radyo, televizyon, dergi, gazeteden, \%24'ü sağlık çalışanlarından duyduğunu belirtmiştir. Sarı nokta ile ilgili bilgi soruları doğru yanıt 1 puan olacak şekilde puanlanmıştır. Katılımcıların ortalama puanı 5,2 4,8 (Min.0-Maks.19) idi. Sarı nokta hastalığını duyanlarla, tanıdığında sarı nokta hastalığı olanlar daha yüksek puan almıştı. Bilgi puanları karşılaştırıldığında yaş, medeni durum, eğitim durumu, çalışma durumu ve günlük yaşamında güneş gözlügü kullananlar arasında istatistiksel olarak anlamlı fark vardı $(\mathrm{p}<0,05)$. Sonuç: $\mathrm{Bu}$ araştırmada bireylerin sarı nokta hastalığı hakkında ki bilgi düzeylerinin düşük olduğu belirlenmiştir. Sarı nokta hastalığını duyanların oranı duymayanlara göre daha fazlaydı. Duyan bireyler ise en fazla çevresindeki insanlardan, radyo, televizyon, dergi, gazeteden ve sağlık çalışanlarından duymuştu. Görsel ve işitsel iletişim araçları daha etkin kullanılarak bireylerin bilgi düzeyi ve farkındalığı artırılabilir. Hastalarla ilk tıbbi temas noktasını oluşturan aile hekimleri, yaşa bağlı maküla dejenerasyonu ilişkili görme kaybını önlemede önemli bir rol oynayabilir. Düzenli tarama ve artmış kamu bilinci erken tanıyı kolaylaştırabilir.

Anahtar kelimeler: Yaşa bağlı maküla dejenerasyonu, sarı nokta hastalığı, bilgi düzeyi, aile hekimliği

\section{ABSTRACT}

Background: Age-Related Macular Degeneration "AMD" is the most common cause of central vision loss in developed countries over 65 years of age. It is of importance to know the risk factors and regulate life style. Aim: To evaluate the level of individuals 'knowledge and raise their awareness. Method: The present study is planned as a cross-sectional descriptive study. A questionnaire form composed of questions about the socio-demographic data and the level of knowledge about AMD was applied to the patients18 years and over who were admitted to Family Medicine outpatient clinic due to any reasons between December 2015 and March 2016 with face-to-face interviews. SPSS 15.0 program was used for statistical analysis, a p level of <0,05 was considered statistically significant. Results: Of the 451 participants 242 (53.7\%) were female. 55.4\% had heard of AMD. About $27 \%$ of the patients who heard of AMD reported that they heard from the people around, 25\% from radio, television, magazines, newspapers and 24\% from health care workers. Questions about AMD were scored so as the correct answer to have 1 point. The mean score was 5,2 $\pm 4,8$ (Min.0-Max.19). Those who have heard about AMD and whose relatives had been diagnosed with AMD had higher scores. When the knowledge scores were compared, there was a statistically significant difference in age, marital status, educational status, working status and daily life using sunglasses ( $p<0.05$ ). Conclusion: The present study has revealed that level of knowledge about AMD was insufficient. Ratio of the patients who heard about AMD was higher than those who did not. Radio, television, magazines, newspapers and health care workers were found as the most common source of knowledge. Knowledge and awareness of individuals can be improved trough more effective use of audio visual media. Family physicians who are the first point of medical contact with patients, can play an important role fir prevention of age-related macular degeneration-related loss of vision. Regular screening and increased public awareness can facilitate early diagnosis.

Key words: Age-related macular degeneration, knowledge, family medicine

Received Date / Geliş Tarihi: 11.06.2018 Accepted Date / Kabul Tarihi: 26.07.2018

${ }^{1}$ Dokuz Eylül Üniversitesi Tıp Fakültesi Aile Hekimliği AD

${ }^{2}$ Dokuz Eylül Üniversitesi Tıp Fakültesi Göz Hastalıkları AD

*Address for Correspondence / Yazışma Adresi: Bolluk A. Dokuz Eylül Üniversitesi Tıp Fakültesi Aile Hekimliği AD, İzmir, TÜRKIYYE

E-mail: aslihanciflik@hotmail.com 


\section{GíRIŞ}

Yaşa bağlı maküla dejenerasyonu (YBMD) 50 yaş üzerindeki olgularda makülada pigmenter ve atrofik değişikliklerle birlikte görülen bir klinik görünüm olarak tanımlanmış olup merkezi görme keskinliğinde ilerleyici azalma ile karakterizedir. ${ }^{1}$ İlk tanımlamanın ardından yaşlı hastalarda "senil maküler eksudatif retinitis" olarak adlandırılmış, daha sonra maküla altındaki büyük kanamanın "senil diskiform maküla dejenerasyonu" olduğu, senil maküla dejenerasyonunda pigment epiteli altı alanın koroidden gelen yeni damarlarla kaplandığ bildirilmiştir. $^{2}$ Ayrıca makülanın diskiform dekolmanı ile sonlanan koryo-kapillerlerdeki eksudatif reaksiyon anlamında "senil maküla koroid dejeneresansı" terimi kullanılmıştır. ${ }^{3}$ Günümüzde yaygın olarak Yaşa Bağlı Maküla Dejenerasyonu "YBMD" terimi kullanılmaktadır. YBMD, gelişmiş ülkelerde 65 yaş ve üzeri kişilerde santral görme kaybının en sık nedeni olarak karşımıza çıkar. ${ }^{4-7}$ Yaşa bağlı maküla dejenerasyonun sıklığı 65-74 yaş arasında \% 10, 75 yaş üzerinde \% 25 olarak bulunmuştur, bu nedenle önemli bir toplum sağlığ 1 sorunu olarak değerlendirilmiştir. ${ }^{8-9}$

Yaşa bağlı maküla dejenerasyonunun iki tipi vardır: Kuru Tip (non-neovasküler) YMBD ve Yaş tip (neo-vasküler) YBMD. ${ }^{10}$

Makula dejenerasyonunun risk faktörleri arasında yaş (major risk faktörü), ırk (Kafkas 1rkında daha sık), kalıtım (aile öyküsü), sigara (riski 2 kat artırır) sayılabilir. Hipertansiyon ve diğer vasküler risk faktörleri ile ilişkili gibi görünmektedir. Diyete bağlı faktörlerden yüksek yağ alımı ve obezite YBMD'yi tetiklerken, yüksek antioksidan alımı bazı gruplarda koruyucu etkiye sahiptir. Diğer faktörlerden örneğin katarakt cerrahisi, mavi iris rengi, aşırı güneşe maruziyeti, kadın cinsiyetten şüphe edilmektedir, ancak etkileri kesin değildir. ${ }^{11}$

Hastaların hekime başvurusunda sıklıkla görme keskinliğinde azalma, santral skotom ve metamorfopsi semptom olarak karşımız çıkar. Bulgular arasında daha az görülenler kontrast duyarlılıkta azalma, renkli görmede azalma, fotopsi ve artmış kamaşma duyarlılığıdır.

Neo-vasküler YBMD'de semptomların görülmesinden önce erken tanı için düzenli göz kontrolleri ve Amsler grid kartının kullanımı önem taşır. Amsler grid kartıyla yapılan değerlendirmede çizgilerde düzensizlik ve eğrilme belirtilmesi, çizgilerin renklerinde değişiklikler veya merkezdeki noktaya odaklayamama gibi bulgular neo-vasküler YBMD düşündürebilir. ${ }^{12}$
Yaş tip sarı nokta hastalığında son yıllarda en çok uygulanan tedavi göz içine anti-VEGF (Vasküler Endotelyal Growth Factor) ilaç enjeksiyonları olup bu ilaçlar, kanamalara ve sıvı birikimlerine yol açarak görmeyi azaltan yeni anormal damar oluşumlarını etkileyerek hastalığın ilerlemesine engel olurlar. ${ }^{13}$

Yaşam süresinin uzamasıyla birlikte kronik hastalıkların çoğaldığı bilinmektedir. Günümüzde yaşa bağlı görülen kronik hastalıklar arasında maküler dejenerasyondan da söz edilebilir. İleri yaş dönemlerinde bireylerin YBMD hakkındaki bilgileri, duruma özgü risk faktörleri ve erken tanıma açısından önem arz etmektedir. Bu nedenle YBMD'nin risk faktörlerinin bilinmesi, yaşam tarzının düzenlenmesi, sigaranın bırakılması sağlığın korunmasında önemli yer tutar. Ayrıca konuya özgün kısa ve kolayca yapılan Amsler grid testinin uygulanabilmesi erken tanı için önemlidir. Yapılan araştırmalar değerlendirildiğinde çoğunlukla YBMD görülen hastalarla yapılan çalışmalar olup konuyla ilgili bilgi durumu üzerine yapılan çalışmalarda bireylerin bilgi durumlarını yeterli ifade ettikleri ancak konuya aşina olmadıkları belirtilmektedir. ${ }^{14-15}$ Stevens ve ark. nın çalışmasında katılımcılar yeterli bilgiye sahip olmadıklarını ifade etmişlerdir. ${ }^{16}$

$\mathrm{Bu}$ çalışmada Dokuz Eylül Üniversitesi Tıp Fakültesi Aile Hekimliği Polikliniklerine herhangi nedenle başvuran bireylerin yaşa bağlı makülar dejenerasyon hastalığı hakkındaki bilgi durumu ve farkındalıklarını araştırarak katılımcıların YBMD hakkındaki bilgi ve farkındalıklarına katkı sağlamayı amaçladık.

\section{GEREÇ VE YÖNTEM}

Kesitsel tanımlayıcı araştırma olarak planlanan çalışmamıza katılmayı kabul eden tüm bireylere sosyo-demografik veriler ve sarı nokta hastalığı hakkındaki bilgi düzeyinin sorgulandığı anket formu yüz yüze görüşme yöntemiyle uygulandı. Çalışmamız için hastanemiz etik kurulu onayı alınmıştır. Anketimizde sarı nokta hastalığı hakkında 19 adet bilgi sorusu bulunmaktadır. Bilgi içeren önermelerin değerlendirilmesinde "Kat1liyorum", "Fikrim yok" ve "Katılmıyorum" olarak 3'lü Likert uygulanmıştır. Veriler değerlendirilirken doğru yanıta 1 , yanlış ve fikrim yok yanıtına 0 puan verilmiştir. Veriler SPSS 15.0 paket programı kullanılarak frekans, ki-kare ve $\mathrm{t}$ testleri yapılmış, istatistiksel analizlerde $\mathrm{p}<0.05$ anlamlı kabul edilmiştir.

\section{BULGULAR}

Araştırmaya 242 kadın (\%53,7), 209 erkek (\%46,3) olmak üzere toplam 451 birey alınmıştır. Yaş 
ortalaması 35,0 $\pm 14,7$ (Min:18 Maks:76) yıl olup 18-24 yaş grubu \% 38,8 ile çoğunluğu oluşturmaktadır. Katılımcıların sosyo-demografik özelliklerine göre dağılımı Tablo 1 ve Tablo 2'de gösterilmiştir.

\begin{tabular}{|c|c|c|}
\hline & $n(n=451)$ & Yüzde (\%) \\
\hline \multicolumn{3}{|l|}{ Cinsiyet } \\
\hline Kadın & 242 & 53,7 \\
\hline Erkek & 209 & 46,3 \\
\hline \multicolumn{3}{|l|}{ Yaş } \\
\hline $18-24$ y1l & 175 & 38,8 \\
\hline $25-34$ yıl & 73 & 16,2 \\
\hline $35-44$ y1l & 84 & 18,6 \\
\hline $45-54$ yil & 58 & 12,9 \\
\hline $55-64$ y1l & 38 & 8,4 \\
\hline 65 ve üzeri & 23 & 5,1 \\
\hline \multicolumn{3}{|l|}{ Çalışma Durumu } \\
\hline Sağlık alanında çalışıyor & 54 & 12 \\
\hline $\begin{array}{lll}\text { Sağlık } & \text { alanı } & \text { dışında } \\
\text { çalışıyor } & & \\
\end{array}$ & 107 & 23,7 \\
\hline Ev hanımı & 42 & 9,3 \\
\hline Emekli & 65 & 14,4 \\
\hline Çalışmıyor & 8 & 1,8 \\
\hline Sağlık alanında öğrenci & 165 & 36,6 \\
\hline \begin{tabular}{lll|} 
Sağlık & alanı & dışında \\
öğrenci & & \\
\end{tabular} & 10 & 2,2 \\
\hline \multicolumn{3}{|l|}{ Medeni Durumu } \\
\hline Bekar & 236 & 52,3 \\
\hline Evli & 183 & 40,6 \\
\hline Eşi vefat etmiş & 15 & 3,3 \\
\hline Boşanmış-ayrı yaşıyor & 17 & 3,8 \\
\hline \multicolumn{3}{|l|}{ Eğitim Durumu } \\
\hline Okuryazar & 4 & 0,9 \\
\hline İlkokul & 36 & 8 \\
\hline Ortaokul & 26 & 5,8 \\
\hline Lise & 225 & 49,9 \\
\hline Üniversite & 138 & 30,6 \\
\hline Yüksek lisans ve üzeri & 22 & 4,9 \\
\hline \multicolumn{3}{|l|}{ Ekonomik Durum } \\
\hline Geliri giderinden az & 141 & 31,3 \\
\hline Geliri giderine eşit & 252 & 55,9 \\
\hline Geliri giderinden fazla & 58 & 12,9 \\
\hline
\end{tabular}

Bilgi içeren önermelere verilen yanıtlar değerlendirildiğinde ortalama bilgi puanı 5,2 $\pm 4,8$ (Min.0-Maks.19), ortanca bilgi puanı 4,0'dır.
Katılımcıların çoğunluğu \%68,1, (n=307) sarı nokta hastalığının gözü ilgilendiren bir hastalık olduğu yanıtını vermiştir, bu soru, $\% 68,1$ oranı ile tüm sorular içinde en fazla oranda doğru yanıtlanmıştı. En çok doğru bilinen ikinci önerme 244 katılımcının doğru cevapladığı "Sarı nokta hastalığında görme kaybı, göz önünde karartılar, görme kalitesinde bozulmalar, renkli görmede bozulmalar görülebilir" önermesidir $(\% 54,1)$. Bu iki bilginin katılımcılar arasında doğru yanıtlanma oranı fazladır. Diğer önermelerin ise yanlış cevaplanma oranı doğru yanıta göre daha fazla bulunmuştur. En çok yanlış yanıtlanan önerme $\% 88,7$ ile "Sarı nokta hastalığında tedavi süresince kan ve idrar tahlili yapılmalıdır" bilgisidir. En fazla yanlış yanıtlanan ikinci önerme ise \%87,6 ile "Sarı nokta hastalığının tedavisinde göz içine iğne yapılması hastalığın ilerleyişini azaltır" önermesidir. Katılımcıların yanıt oranları Tablo 3 'te gösterilmiştir.

Katılımcılar sarı nokta hastalığını sırasıyla en çok çevresindekilerden, televizyon, radyo, dergi ve gazeteden ve sağlık çalışanlarından duyduğunu ifade etmiştir. Çalışmaya katılanların sarı nokta hastalığını duyma durumuna göre bilgi puanları karşılaştırıldığında anlamlı fark vardır $(\mathrm{p}<0.001)$. Tanıdığında sarı nokta hastalığı olanların bilgi puanları, olmayanlara göre yüksektir ( $p<0.001$ ). Günlük yaşamında güneş gözlüğü kullananların puanları kullanmayanlara göre $(\mathrm{p}<0.05)$, uzak ya da yakın gözlük kullananların bilgi puanları da kullanmayanlara göre daha fazladır $(p<0.05)$. Çalışmaya katılanların yaş grupları arasında doğru bilgiye sahip olma açısından anlamlı fark bulunmuştur ( $\mathrm{p}<0.01$ ). Çalışanlar, evli olanlar, eğitim düzeyi yüksek olanlar ve gelir düzeyi yüksek olanların bilgi puanları daha yüksektir $(\mathrm{p}<0.05)$. Sarı nokta hastalığını duyma kaynağına göre bilgi puanları karşılaştırıldığında gruplar arası anlamlı fark vardır $(\mathrm{p}<0.001)$ (Tablo 4 ve Tablo 5).

\begin{tabular}{|l|l|l|l|}
\hline $\begin{array}{l}\text { Tablo 2. Katılımcıların } \\
\text { özelliklerine göre dağılımı }\end{array}$ \\
\hline \multirow{3}{|c|}{} & $\begin{array}{l}\text { n } \\
(\mathbf{n = 4 5 1})\end{array}$ & $\begin{array}{l}\text { Yüzde } \\
(\%)\end{array}$ \\
\hline \multirow{2}{*}{$\begin{array}{c}\text { Tütün ve tütün ürünü } \\
\text { kullanımı }\end{array}$} & Evet & 145 & 32,2 \\
\cline { 2 - 4 } & Hayır & 306 & 67,8 \\
\hline Sarı nokta hastalığını duyma & Evet & 250 & 55,4 \\
\cline { 2 - 4 } & Hayır & 201 & 44,6 \\
\hline \multirow{2}{*}{$\begin{array}{l}\text { Sarı nokta hastalığı görülen } \\
\text { tanıdığa sahip olma }\end{array}$} & Evet & 54 & 12 \\
\cline { 2 - 4 } & Hayır & 397 & 88 \\
\hline Güneş gözlüğ̈ kullanma & Evet & 245 & 54,3 \\
\cline { 2 - 4 } & Hayır & 206 & 45,7 \\
\hline \multirow{2}{*}{$\begin{array}{l}\text { Herhangi bir göz hastalığı } \\
\text { olma }\end{array}$} & Evet & 196 & 43,5 \\
\cline { 2 - 4 } & Hayır & 255 & 56,5 \\
\hline $\begin{array}{l}\text { Uzak ya da yakın gözlüğü } \\
\text { kullanma }\end{array}$ & Evet & 224 & 49,7 \\
\cline { 2 - 4 } & Hayır & 227 & 50,3 \\
\hline
\end{tabular}




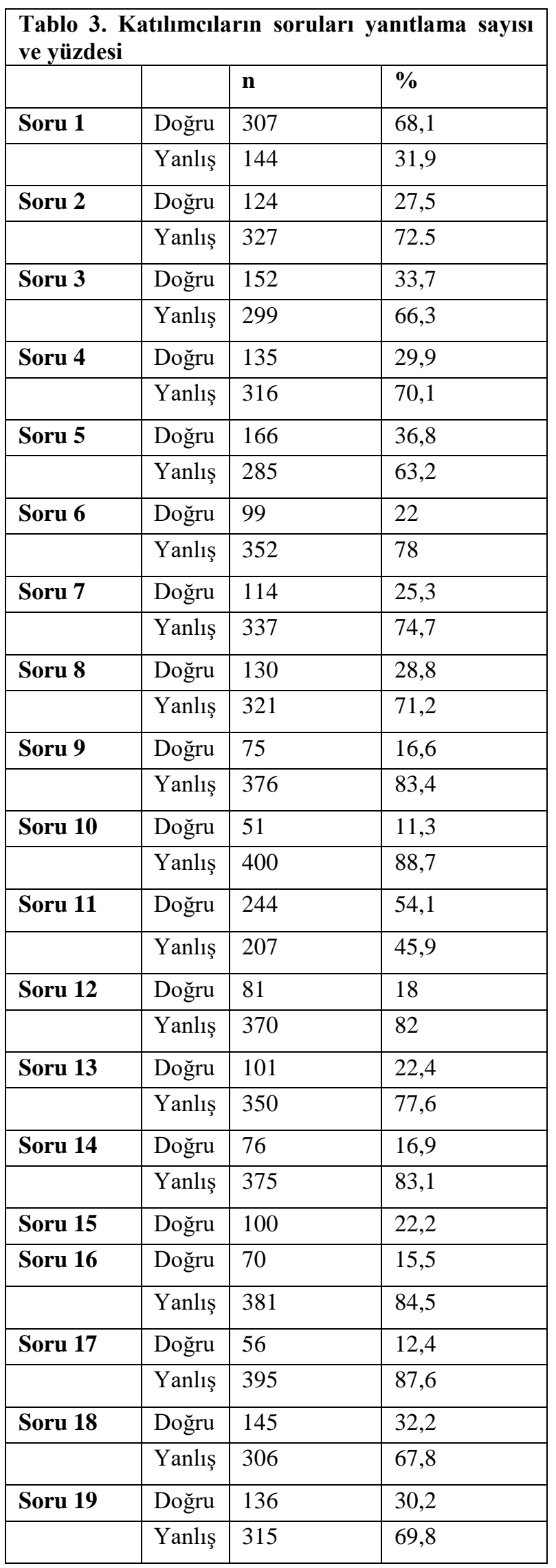

\begin{tabular}{|c|c|c|c|c|c|}
\hline \multicolumn{6}{|c|}{$\begin{array}{l}\text { Tablo 4. Katılımcıların özelliklerinin bilgi } \\
\text { puanlarına göre karşılaştırılması }\end{array}$} \\
\hline Özellikler & $\begin{array}{l}n \\
(n=451)\end{array}$ & $\begin{array}{l}\text { Yüzde } \\
(\%)\end{array}$ & $\begin{array}{l}\text { Bilgi } \\
\text { puanı }\end{array}$ & $\begin{array}{l}\text { Standart } \\
\text { Sapma }\end{array}$ & $\mathbf{p}$ \\
\hline \multicolumn{6}{|c|}{ Sarı nokta hastalığını duyma } \\
\hline Evet & 250 & 55,4 & 7,44 & 4,38 & $<0,001^{*}$ \\
\hline Hayır & 201 & 44,6 & 2,5 & 3,63 & \\
\hline \multicolumn{6}{|c|}{ Sarı nokta hastalığı görülen tanıdığa sahip olma } \\
\hline Evet & 54 & 12 & 7,85 & 4,32 & $<0,001^{*}$ \\
\hline Hayır & 397 & 88 & 4,88 & 4,69 & \\
\hline \multicolumn{6}{|c|}{ Güneş gözlüğü kullanma } \\
\hline Evet & 245 & 54,3 & 5,67 & 4,87 & $<0,05^{*}$ \\
\hline Hayır & 206 & 45,7 & 4,72 & 4,55 & \\
\hline \multicolumn{6}{|c|}{ Uzak ya da yakın gözlüğü kullanma } \\
\hline Evet & 224 & 49,7 & 5,7 & 4,81 & $<0,05^{*}$ \\
\hline Hayır & 227 & 50,3 & 4,78 & 4,64 & \\
\hline
\end{tabular}

* Independent sample t test

\section{TARTIŞMA}

Araştırmamızda katılımcıların yarısı sarı nokta hastalığını duyduğunu ifade etmiştir. Ancak sarı nokta hastalığının yaşlılardaki en sık körlük nedeni olduğunu az bir bölümü doğru yanıtlamıştır.

Uluslararası bir araştırmaya göre yetişkinlerin sadece \%2'si 50 yaş üzerinde önde gelen körlük nedeninin YBMD olduğunu düşünmüştü ve bu araştırmaya katılanların büyük çoğunluğu YBMD'ye aşina değildir. ${ }^{17}$ Çalışmamız üniversite hastanesinde yapıldığından polikliniğimize başvuranlar arasında sağlık yerleşkesi çalışanları ve öğrenciler çoğunluğu oluşturmaktaydı. $\mathrm{Bu}$ katılımcıların ortalama bilgi puanı ortalamanın üzerinde bulunmuştur. Ancak toplam puanı değerlendirildiğinde yine de düşük olduğu söylenebilir. Yani çalışma sonuçlarımıza göre sağlık alanında çalışanlar ve öğrencilerin de sarı nokta hastalığı hakkında yeterli bilgisi yoktur.

Çalışmamızda katılımcıların bilgi puanı ortalamaları yaş grupları arasında farklı bulunmuştur $(p<0.01)$. Toplam puan ortalamasının altında olan grup 35-44 yaş grubudur. Daha küçük yaş gruplarında ortalamanın üzerindeki bilgi düzeyi genç yaş, eğitimli grup olması ve bu grubun çoğunluğunun sağlıkla ilgili olmasından kaynaklanıyor olabilir. Orta yaşlara doğru konuya ilgi ve farkındalığın azaldığı, ileri yaşlarda görmede kayıpların yaşlanmasıyla birlikte ilginin artmaya başladığı düşünülebilir. Bu durumla ilgili olarak yapılan izlem çalışmalarında farkındalığın artırılabileceği belirtilmektedir. ${ }^{15}$ 


\begin{tabular}{|c|c|c|c|c|c|}
\hline Özellikler & $n(n=451)$ & Yüzde (\%) & Bilgi puanı & Standart Sapma & $\mathbf{p}$ \\
\hline \multicolumn{6}{|l|}{ Yaş } \\
\hline $18-24$ y1l & 175 & 38,8 & 5,95 & 4,51 & \\
\hline $25-34$ y1l & 73 & 16,2 & 5,89 & 5,54 & \\
\hline $35-44$ yil & 84 & 18,6 & 3,69 & 3,81 & $<0,01 * *$ \\
\hline $45-54$ y1l & 58 & 12,9 & 5,09 & 4,7 & \\
\hline $55-64 \mathrm{y} 11$ & 38 & 8,4 & 4,29 & 4,78 & \\
\hline 65 ve üzeri & 23 & 5,1 & 5,35 & 5,73 & \\
\hline \multicolumn{6}{|l|}{ Çalışma durumu } \\
\hline Sağlık alanında çalışıyor & 54 & 12 & 6,52 & 5,15 & \\
\hline Sağlık alanı dışında çalışıyor & 107 & 23,7 & 3,71 & 3,86 & \\
\hline Ev hanımı & 42 & 9,3 & 3,05 & 4,54 & \\
\hline Emekli & 65 & 14,4 & 5,88 & 5,12 & $<0,001 * *$ \\
\hline Çalışmıyor & 8 & 1,8 & 2,25 & 2,55 & \\
\hline Sağlık alanında öğrenci & 165 & 36,6 & 6,32 & 4,62 & \\
\hline Sağlık alanı dışında öğrenci & 10 & 2,2 & 4,2 & 5,16 & \\
\hline \multicolumn{6}{|l|}{ Medeni durum } \\
\hline Bekar & 236 & 52,3 & 6,28 & 4,66 & \\
\hline Evli & 183 & 40,6 & 3,84 & 4,52 & \\
\hline Eşi vefat etmiş & 15 & 3,3 & 5,13 & 4,66 & $<0,001 * *$ \\
\hline Boşanmış-ayrı yaşıyor & 17 & 3,8 & 5,82 & 4,52 & \\
\hline \multicolumn{6}{|l|}{ Eğitim durumu } \\
\hline Okuryazar & 4 & 0,9 & .00 & .000 & \\
\hline İlkokul & 36 & 8 & 3,44 & 4,88 & \\
\hline Ortaokul & 26 & 5,8 & 3,15 & 4,46 & $<0,01 * *$ \\
\hline Lise & 225 & 49,9 & 5,63 & 4,61 & \\
\hline Üniversite & 138 & 30,6 & 5,67 & 4,83 & \\
\hline Yüksek lisans ve üstü & 22 & 4,9 & 4,91 & 4,63 & \\
\hline \multicolumn{6}{|l|}{ Ekonomik durum } \\
\hline Geliri giderinden az & 141 & 31,3 & 4,28 & 4,45 & \\
\hline Geliri giderine eşit & 252 & 55,9 & 5,61 & 4,76 & $<0,05^{* *}$ \\
\hline Geliri giderinden fazla & 58 & 12,9 & 5,97 & 5,08 & \\
\hline \multicolumn{6}{|c|}{ Sarı nokta hastalığını nereden duydunuz? } \\
\hline Sağlık çalışanlarından & 56 & 22,4 & 8,91 & 3,97 & \\
\hline Çevremdeki insanlardan & 54 & 21,6 & 6,17 & 4,76 & \\
\hline Televizyon, radyo, dergi, gazeteden & 53 & 21,2 & 6,08 & 4,1 & \\
\hline İnternetten & 15 & 6 & 7,67 & 3,45 & $<0,01 * *$ \\
\hline Diğer & 40 & 16 & 7,93 & 4,67 & \\
\hline Birden fazla seçenek işaretleyen & 32 & 12,8 & 8,53 & 3,91 & \\
\hline
\end{tabular}

**Anova testi 
Katılımcıların tümü değerlendirildiğinde doğru yanıt oranı ancak 2 soruda yüksek bulunmuştur, yanlış yanıtlar daha fazladır. Çalışmaya katılanların yaş, medeni durum ve eğitim durumuna göre bilgi puanlarına bakıldığında gruplar arasında anlamlı fark vardır $(\mathrm{p}<0,05)$. Bilgi puanları çalışma durumları ve gelir düzeylerine göre karşılaştırıldığında da aralarındaki fark anlamlıdır ( $\mathrm{p}<0,05)$. Kornbluth ve ark. nın çalışmasında 55 yaş üzerindekilerin ve kadınların bilgi düzeyi daha yüksek bulunmuştur. ${ }^{18}$

Sarı nokta hastalığını duyanların ortalama bilgi puanları daha yüksek bulunmuştur. Sarı nokta hastası tanıdığ1 olanlar arasında ortalama bilgi puanları da daha yüksektir $(\mathrm{p}<0,05)$, hastalığa aşina olmaları buna neden olabilir. Sarı nokta hastalığını duyma kaynağına göre bilgi puanları karşılaştırıldığında gruplar arası anlamlı fark görülmüştür $(\mathrm{p}<0,05)$. Bu sonuçlar Singapur ve Çin'de yapılan çalışma sonuçlarıyla benzerlik göstermektedir. ${ }^{15,19}$

Günlük yaşamında güneş gözlüğü kullananların bilgi puanları, kullanmayanlara göre daha yüksek bulunmuştur ancak tesadüfen mi yoksa korunmak açısından mı gözlük kullandıkları belirsizdir. Uzak ya da yakın gözlük kullanan katılımcıların bilgi puanları, kullanmayanlara göre karşılaştırıldığında anlamlı fark varken $(\mathrm{p}<0,05)$ bilgi puanı açısından herhangi göz hastalığı bulunanlarda anlamlı fark bulunmamıştır.

Araştırmamızdaki katılımcı sayısının kısıtlı olmasından dolayı daha geniş çaplı yapılacak araştırmaların daha gerçekçi sonuçlar vereceğini düşünmekteyiz.

\section{SONUÇ}

$\mathrm{Bu}$ araştırmada bireylerin sarı nokta hastalığı hakkında bilgi düzeylerinin düşük olduğu, kamu spotu olmasına rağmen çoğu kişinin sarı nokta hastalığını duymadığı belirlenmiştir. Sarı nokta hastalığını duyanlar duymayanlara göre daha fazladır. Duyan bireyler ise en fazla çevresindeki insanlardan, radyo, televizyon, dergi, gazeteden ve sağlık çalışanlarından duyduğunu belirtmektedir. $\mathrm{Bu}$ açıdan değerlendirildiğinde daha fazla görsel ve işitsel iletişim araçları kullanılarak ve konunun önemi daha sik vurgulanarak bireylerin bilgi ve farkındalığının artırılmasına katkıda bulunulabilir.

Sarı nokta hastalığı açısından yapılacak düzenli taramalar ve artırılmış kamu bilinci erken tanıyı kolaylaştırabilir. Birinci basamak hekimleri YBMD taranmasında ve gerekli görülen hastaların oftalmoloğa sevk edilmesinde önemli bir yere sahiptir. ${ }^{20}$ Aile hekimliği sağlık hizmeti sunumunda ilk tıbbi temas noktasını oluşturur ve aile hekimliği disiplininde koruyucu hekimliğin özel bir yeri vardır. $^{21}$ Aile hekimleri, yaşa bağlı maküla dejenerasyonu olan hastalarda görme kaybını önlemede önemli bir rol oynayabilir.

\section{KAYNAKLAR}

1. Haab O. Erkrankungen der Maculalutea. Centralblat Augenheilkd 1885;9:384-91.

2. Atmaca LS. Senil dissiform makula dejeneresansı. Turaçlı ME, editör. Maküla Hastalıkları, retina arter ven tıkanıklıkları, Ankara: IV. Ulusal Oftalmoloji Kursu; 1984. S. 23-35.

3. Gass JMD. Pathogenesis of disciform detachment of the neuro epithelium: (1. General conseptsand classification. III. Senile disciform macular degeneration.) Am J Opthalmol. 1967;63:573-85.

4. Leibowitz HM, Krueger DE, Maunder LR, Milton RC, Kini MM, Kahn HA, et al. The Framingham Eye Study Monograph: an ophthalmological and epidemiological study of cataract, glaucoma, diabeticretinopathy, maculardegeneration, andvisualacuity in a general population of 2631 adults, 1973-1975. SurvOphthalmol. 1980;24(Suppl.):335-610.

5. Klein R, Klein BE, Jensen SC, Meuer SM. Thefive-year incidence and progression of agerelated maculopathy: the Beaver Dam Eye Study. Ophthalmology 1997;104(1):7-21.

6. Rahmani B, Tielsch JM, Katz J, Gottsch J, Quigley H, Javitt J, et al. Thecause-specific prevalence of visual impairment in an urban population .The Baltimore Eye Survey. Ophthalmology 1996;103(11):1721-6.

7. Gass JDM. Stereoscopic atlas of maculardiseases; diagnosis and treatment, 4th edn. St Louis: CV Mosby; 1997.p.70-2.

8. Lotery A, Xu X, Zlatava G, Loftus J. Burden of illness, visual impairment and Health resource utilisation of patients with neovascularagerelated macular degeneration: results from the UK cohort of a five-countrycrosssectionalstudy. $\mathrm{Br} \quad \mathrm{J}$ Ophthalmol. 2007;91(10):1303-7.

9. Liu TY, Shah AR, Del Priore LV. Progression of lesion size in untreated eyes with exudative age-related macular degeneration a metaanalysis using Lineweaver-Burk plots. JAMA Ophthalmol. 2013;131(3):335-40.

10. Odwyer PA. ve Akova YA. Temel göz hastalıkları. 3.Baskı. Ankara:Güneş Tıp Kitabevleri;2015.p.677-685.

11. KanskiJJ. and Bowling B. Klinik OftalmolojiSistemik Yaklaşım. Akkova YA, çeviri editörü.7. Baskı. Ankara:Güneş Tıp Kitabevleri; 2015.p.611-617. 
12. Candemir B. Yaş tip yaşa bağlı maküla dejenerasyonunda görme keskinliğinin, Floresein Anjiografi ve Optik Koherens Tomografi bulguları ile ilişkisi.T.C.S.B. Göztepe Eğitim ve Araştırma Hastanesi Göz Hastalıkları Uzmanlık Tezi. İstanbul: 2009:812.

13. Barthelmes D, Campain A, Nguyen P, Arnold JJ, McAllister IL, Simpson JM, et al. Blindness! Project Investigators. Effects of switching from ranibizumab to aflibercept in eyes with exudativeage-related macular degeneration. Br J Ophthalmol.2016;100:16405.

14. Burgmüller $M$, Cakmak N, Weingessel B, Vécsei C, Vécsei-MarlovitsetPV.Patient knowledge concerning age-related macular degeneration: an AMD questionnaire. Wien Klin Wochenschr, 2017;129:345-50.

15. Sanjay S, Chin YC, Teo HT, Ong SX, Toh SHF, KhongMH. A follow-upsurvey on the knowledge of age-related macular degeneration and its risk factors among Singapore residents after 5 years of nation-wide awareness campaigns. Ophthalmic Epidemiology 2014;21(4):230-6.
16. Stevens R,Bartlett H, Walsh R, CookeetR. Age-related macular degeneration patients' awareness of nutritional factors. British Journal of Visual Impairment, 2014;32(2):77-93.

17. Cimarolli VR, Laban-Baker A, Hamilton WS, Stuenet C. Awareness, knowledge, and concern about age-related macular degeneration. Educational Gerontology 2012;38(8):530-8.

18. Kornbluth, JG,Wu G, RosenthalJ, YoonY, MossyA, Chowanadi saiM, WongM, EstreicherM.B. Using a Questionnaire to Assess Knowledge of Age Related Macular Degeneration in a Clinical Practice Setting. Investigative Ophthalmology \& Visual Science 2003;44(13):1808-1808.

19. Zhang CX, Zhang GM, Ma N, Xia S, Yang JY, Chen YX. Awareness of Age-related Macular Degeneration and Its Risk Factors among Beijing Residents in China. Chin Med J 2017;130:155-9.

20. Bressler NM. Early detection and treatment of neovascular age-related macular degeneration. J Am Board FamPract 2002;15(2):142-52.

21. http://www.woncaeurope.org/sites/default/files/ documents/WONCAdefinitionTurkishversion.p df 